\title{
Preparation, Optimization and Characterization of Eudragit Coated Chitosan Piroxicam Microspheres Intended for the Treatment of Rheumatoid Arthritis
}

Kalla Madhavi ${ }^{1 *}$, S Shobha Rani ${ }^{2}$, Shaheda Khatoon ${ }^{1}$ and Choppari Vijender ${ }^{3}$

${ }^{1}$ Department of Pharmacy, Care College of Pharmacy, Kakatiya University, Warangal, Telangana, India

${ }^{2}$ JNTU, Kukatpally, Hyderabad, India

${ }^{3}$ University College of Pharmaceutical sciences, Kakatiya University, Telangana, India

\begin{abstract}
As a novel drug delivery approach, piroxicam an anti rheumatoid drug is loaded in microspheres prepared by chitosan as a polymer and coated with eudragit S-100 to prepare colon specific microspheres which increases the bioavailability of the drug to the targeted area and in a controlled manner and reduces GI related side effects. In the present study chitosan microspheres were prepared using emulsion crosslinking technique, glutaraldehyde as a crosslinker and microencapsulation using phase coacervation technique. Optimization is done by varying drugpolymer ratio (1:2 to $1: 8)$, emulsifier concentration, i.e., span $80(0.5 \mathrm{ml}, 0.75 \mathrm{ml}, 1 \mathrm{ml})$, stirring speed (500 rpm, 1000 $\mathrm{rpm}, 1500 \mathrm{rpm}, 2000 \mathrm{rpm}, 2500 \mathrm{rpm})$, cross-linker concentration $(2.5 \mathrm{ml}, 5 \mathrm{ml}, 10 \mathrm{ml}$ ) and coat-core ratio from 1:2 to 1:6. The prepared chitosan microspheres showed high entrapment efficiency about $97.29 \%$ with percent yield 90.26 . In the present study FTIR studies confirmed the absence of interactions between the pure drug, i.e., piroxicam and the excipients used. SEM images revealed that the prepared chitosan microspheres were spherical in shape with rough surface and particle size ranged from 90.21 to $172 \mu \mathrm{m}$. Showed good drug release profile for both coated and uncoated chitosan piroxicam microspheres of about $86 \%$ and $96 \%$. Drug release kinetics showed that microspheres followed korsemeyer peppas model indicating the drug diffusion mechanism from polymer matrix.
\end{abstract}

Keywords: Chitosan microspheres; Emulsion method; Eudragit coated microspheres; Piroxicam microspheres

\section{Introduction}

In the view to deliver drug efficiently to specific organs a novel way, i.e., polymeric microspheres have been designed, and to overcome some of conventional therapy problems such as poor stability, low solubility, increase frequency of administration due to shorter half life, increase side effects, decrease patient compliance, etc. Thus novel drug delivery system is needed and thus designed to improve the healing efficiency of given pure drug, to deliver at the right time, increasing compliance and minimizing side effects. One such delivery system is microspheres as drug carriers [1].

Rheumatoid arthritis is most chronic autoimmune disease causing inflammation of joints, main symptom including morning stiffness. Piroxicam an NSAID frequently used for symptom relief but are associated with GI side effects where safety becomes primary requisite this can be achieved by polymeric microspheres and to achieve chronopharmacotherapy in order to increase patient compliance in the treatment of rheumatoid arthritis [2]. The present work was to prepare colon specific polymeric microspheres because of the long residence time in colon, i.e., $72 \mathrm{~h} \mathrm{[3]}$.

\section{Materials and Methods}

Piroxicam was obtained from TRIDENT Pvt Ltd, Hyderabad (India), eudragit S100 was purchased from HiMedia laboratories, Chitosan of 55KD and all other materials used were of pharmaceutical grade.

\section{Method of preparation}

Chitosan microspheres were prepared by using emulsion method and glutaraldehyde was used as a cross-linker. A ( $2 \% \mathrm{w} / \mathrm{v})$ chitosan solution was prepared with about $20 \mathrm{ml}$ of $2 \% \mathrm{v} / \mathrm{v}$ aqueous acetic acid solution in which required amount of piroxicam was added gradually upon stirring. This drug polymer solution was stirred on a magnetic stirrer which was kept overnight. Aqueous phase (internal phase) was dispersed into $100 \mathrm{ml}$ of liquid paraffin and glutaraldehyde, formed microspheres were dried at $50^{\circ} \mathrm{C}$ in hot air oven $[4,5]$.

Microencapsulation of prepared cross-linked chitosan microspheres by phase coacervation technique

Cross-linked chitosan microspheres were dispersed in $10 \mathrm{ml}$ of coating solution which contained $200 \mathrm{mg}$ of eudragit $\mathrm{S} 100$ dissolved in ethanol containing $0.25 \% \mathrm{v} / \mathrm{v}$ span 80 , mixture was agitated for about 5 $\mathrm{min}$ at $500 \mathrm{rpm} .50 \mathrm{ml}$ of $\mathrm{n}$-hexane was added at a rate of $1 \mathrm{ml} / \mathrm{min} \mathrm{kept}$ on stirring. The formed coated microspheres washed with $\mathrm{n}$-hexane for 2-3 times and dried at room temperature [6].

\section{Optimization of the formulation by varying process variables}

Effect of drug polymer ratio: Microspheres were prepared using different drug polymer ratio, i.e., 1:2, 1:3, 1:4, 1:5, 1:6, 1:7 and 1:8 where stirring speed $(2000 \mathrm{rpm})$ and emulsifier concentration $(0.5 \% \mathrm{w} / \mathrm{v})$ were kept constant [7].

Effect of emulsifier concentration: Microspheres were prepared using various concentrations of an emulsifier, i.e., $0.50,0.75,1.0 \mathrm{ml}$ maintaining the stirring speed constant $(2000 \mathrm{rpm})$.

Effect of core-coat ratio: Prepared microsphere were coated using various core-coat ratios $(1: 2,1: 3,1: 4,1: 5,1: 6)$ where drug polymer ratio (1:5) was kept constant [6].

*Corresponding author: Kalla Madhavi, Department of Pharmacy, Care College of Pharmacy, Kakatiya University, Warangal, Telangana, India, Tel: 91-9963073027, E-mail: kallamadhavi@gmail.com

Received February 23, 2016; Accepted April 22, 2016; Published April 26, 2016

Citation: Madhavi K, Rani SS, Khatoon S, Vijender C (2016) Preparation, Optimization and Characterization of Eudragit Coated Chitosan Piroxicam Microspheres Intended for the Treatment of Rheumatoid Arthritis. Pharm Anal Acta 7: 485 doi:10.4172/2153-2435.1000485

Copyright: (c) 2016 Madhavi K, et al. This is an open-access article distributed under the terms of the Creative Commons Attribution License, which permits unrestricted use, distribution, and reproduction in any medium, provided the original author and source are credited. 
Citation: Madhavi K, Rani SS, Khatoon S, Vijender C (2016) Preparation, Optimization and Characterization of Eudragit Coated Chitosan Piroxicam Microspheres Intended for the Treatment of Rheumatoid Arthritis. Pharm Anal Acta 7: 485. doi:10.4172/2153-2435.1000485

\section{Pre formulation studies}

Solubility study: Solubility study of drug was performed in different solvents, i.e., $0.1 \mathrm{~N} \mathrm{HCl}, 4.5 \mathrm{pH}$ acetate buffer, $6.8 \mathrm{pH}$ phosphate buffer, $7 \mathrm{pH}$ phosphate buffer, glacial acetic acid, methanol and water by shake flask method.

Drug excipient compatibility study: The analytical technique used for drug excipient compatibility study was FTIR with attenuated Total Reflectance (ATR) technique. A small portion of a sample was placed on the zinc selenide crystal and spectrum was taken. The IR spectra of the formulation was compared with the IR spectra of pure drug and observed for any spectral changes [8].

\section{Evaluation}

Percent yield: Weight of the prepared microspheres was weighed and $\%$ yield was calculated using the following equation

Percent yield $=$ Practical yield $\times 100 /$ Theoretical yield

Practical yield=Amount of the microspheres collected after the experimental method

Theoretical yield=Total amount of the drug and the excipients used in the preparation

Particle size analysis: Particle size analysis of the prepared microspheres was performed using compound microscope by calibrating eye piece micrometer.

Entrapment efficiency: $25 \mathrm{mg}$ of drug loaded chitosan microspheres were taken in $25 \mathrm{ml}$ of methanol and kept under continuous stirring for about $24 \mathrm{~h}$ and then the sample was centrifuged for $10 \mathrm{~min}$ at 2000 rpm and the supernatant layer was separated and analyzed using UVvisible spectrophotometer at $\chi_{\max } 240 \mathrm{~nm}$. Entrapment efficiency was calculated using the formula [8].

$\%$ Entrapment efficiency $=$ Practical drug loading $\times 100 /$ Theoretical drug loading

Micromeritic properties: Flow property of prepared microspheres was determined using fixed base cone method. Bulk density using bulk density apparatus, tapped density by a $10 \mathrm{ml}$ graduated cylinder and using bulk density and tapped density data; compressibity index and hausner's ratio were calculated.

SEM studies: SEM studies of chitosan microspheres were carried out by gentle sprinkling on an adhesive tape which was fixed on the dies followed by vaccum and high voltage for taking images under high and low resolution.

Stability studies: Stability studies were conducted for the optimized formulation for about 3 months in stability chamber as per ICH guidelines prescribed for tropical countries.

4.5.7 In vitro drug release study: $100 \mathrm{mg}$ of prepared piroxicam microspheres were taken in a dialysis bag, dipped into $900 \mathrm{ml}$ of dissolution medium at $37 \pm 0.5^{\circ} \mathrm{C}$ in a paddle type dissolution apparatus at $50 \mathrm{rpm}$. Study was carried out in $0.1 \mathrm{~N} \mathrm{HCl}$ buffer $(\mathrm{pH} 1.2)$ for first $2 \mathrm{~h}$, then in $\mathrm{pH} 4.5$ phosphate buffer for next $2 \mathrm{~h}$ and then followed by $\mathrm{pH} 7$ phosphate buffer up to $24 \mathrm{~h}$. An aliquot of $5 \mathrm{ml}$ was withdrawn at predetermined time intervals and the samples were analyzed using UV-visible spectrophotometer.

Drug release kinetics: To describe drug release kinetics, release data was fitted in different kinetic models.

\section{Results and Discussion}

In an attempt to reduce side effects of piroxicam for the treatment of rheumatoid arthritis, eudragit S100 coated chitosan microspheres were prepared and evaluated. The evaluation results are discussed below.

\section{Effect of drug to polymer ratio}

As the polymer ratio increased, increase in mean diameter was observed because of increase in viscosity and needed more energy for the particle break down to smaller size particles. The drug entrapment efficiency also increased as the concentration of polymer increased because of high chances of polymer surrounding the drug and thus preventing escape of drug into external solvent and the increase was only up to 1:5 (drug-polymer ratio) and then decreased. As the polymer amount increase even $\%$ yield also increased (Table 1).

\section{Effect of emulsifier concentration}

Without surfactant, i.e., span80, microspheres formed were found to be aggregated. When $0.5 \%$ of span 80 was added it showed formation of stable emulsion and on increasing the concentration of span80, percent yield increased, might be due to increase in number of droplets in emulsion formed (Table 2).

Increase in span 80 concentration decreased the total drug content in the chitosan microsphere, that may be due to solubilizing effect of span 80 on piroxicam during preparation of microspheres and $0.5 \mathrm{ml}$ was the optimized concentration of the emulsifier, as it showed high \% entrapment efficiency.

\section{Effect of stirring speed}

Among the various stirring speed, stirring at $2000 \mathrm{rpm}$ shows a uniform formation of microspheres. Higher than $2000 \mathrm{rpm}$ resulted in rupture of dispersion droplets thus resulted in fewer microsphere formation (Table 3).

\begin{tabular}{|c|c|c|c|}
\hline $\begin{array}{c}\text { Drug polymer } \\
\text { ratio }\end{array}$ & $\begin{array}{c}\text { Mean particle size } \\
(\boldsymbol{\mu m})\end{array}$ & Percent yield & $\begin{array}{c}\text { \% entrapment } \\
\text { efficiency }\end{array}$ \\
\hline $1: 2$ & 90.2 & 81.2 & 74 \\
\hline $1: 3$ & 94.3 & 84.9 & 81.2 \\
\hline $1: 4$ & 98.0 & 86.4 & 85.4 \\
\hline $1: 5$ & 109.0 & 90.2 & 97.2 \\
\hline $1: 6$ & 138.4 & 91.3 & 94.2 \\
\hline $1: 7$ & 145.0 & 92.3 & 92.4 \\
\hline $1: 8$ & 172 & 96.6 & 90 \\
\hline
\end{tabular}

Table 1: Effect of drug to polymer ratio on the particle size, \% yield, entrapment efficiency.

\begin{tabular}{|c|c|c|c|c|}
\hline $\begin{array}{c}\text { Drug polymer } \\
\text { ratio }\end{array}$ & $\begin{array}{c}\text { Emulsifier } \\
\text { concentration } \\
(\mathbf{m l})\end{array}$ & $\begin{array}{c}\text { Mean particle size } \\
(\boldsymbol{\mu m})\end{array}$ & \% yield & $\begin{array}{c}\% \\
\text { Entrapment } \\
\text { efficiency }\end{array}$ \\
\hline $1: 5$ & 0.5 & 107 & 88.2 & 96.2 \\
\hline $1: 5$ & 0.75 & 102 & 89.9 & 95.3 \\
\hline $1: 5$ & 1 & 100.2 & 90.2 & 94.2 \\
\hline
\end{tabular}

Table 2: Effect of emulsifier concentration on particle size, \% yield and entrapment efficiency.

\begin{tabular}{|c|c|c|}
\hline Drug polymer ratio & Stirring speed & Mean particle size $(\boldsymbol{\mu m})$ \\
\hline $1: 5$ & 500 & 389.2 \\
\hline $1: 5$ & 1000 & 349.1 \\
\hline $1: 5$ & 1500 & 205.3 \\
\hline $1: 5$ & 2000 & 110.3 \\
\hline $1: 5$ & 2500 & 87.5 \\
\hline \multicolumn{2}{|c|}{ Table 3: Effect of stirring speed on particle size. } \\
\hline \multicolumn{2}{|c}{}
\end{tabular}


Increase in glutaraldehyde concentration showed on significant effect in the formation of microspheres. As the core coat ratio increased a slight increase in particle size was observed (Table 4).

Flow properties of prepared microspheres were measured and showed to be greater than $25^{\circ} \mathrm{C}$ indicating excellent flow property. Even \% compressibility index (\%) and hausner's ratio values indicated excellent flow property for the prepared microspheres. Bulk density and tapped density found to be less than $1.26 \mathrm{~g} / \mathrm{cc}$ indicating good packing and excellent flow characteristics (Figures 1 and 2).

From the FTIR studies of pure drug and prepared microspheres it was observed that, the intensity and position of the absorption bands had no significant change and thus from the spectrum it is clear that there is no interaction between drug and excipients used in the formulation (Table 5).

SEM images revealed that the prepared microspheres were discrete and spherical shaped with rough outer surface (Figure 3 ).

Release profile from uncoated microspheres was slow but independent of $\mathrm{pH}$ of the dissolution fluid. Decrease in drug release rate might be due to cross linking of microspheres. And also that increase in the concentration of crosslinking agent decreases the amount of drug release this might be due to presence of more crosslinking agent available to react with the $\mathrm{NH}_{2}$ groups of chitosan. In uncoated chitosan microspheres complete drug release (almost 86\%) within 10 $\mathrm{h}$ indicates the need for enteric coating of the formulation for colon delivery (Figures 4-6).

Enteric coated microspheres showed no drug release in simulated gastric fluid for up to $2 \mathrm{~h}$ whereas in simulated intestinal fluid media showed negligible drug release. In $\mathrm{pH} 7$ phosphate buffer drug release was about $96 \%$ in $24 \mathrm{~h}$. Analyzing the overall drug release profile of the coated microspheres, it is evident that microspheres retained their integrity upto $24 \mathrm{~h}$ releasing the drug slowly and consistently.

On filling the release data in kinetic models and comparing the regression values, it is clear that it follows korsemeyer peppas, indicating that the drug release from polymer matrix is by diffusion and showed high slope (n) value which indicates that the release from the prepared microspheres was anomalous (non-fiction) release mechanism.

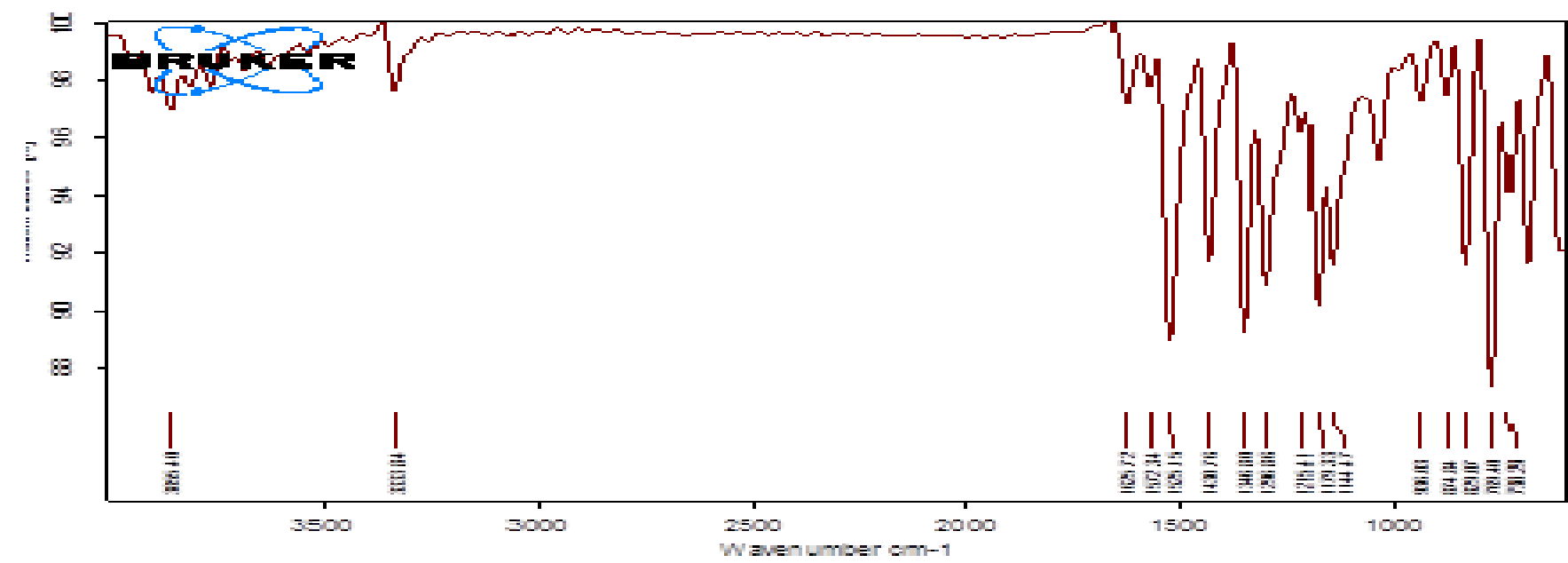

Figure 1: FTIR spectrum of pure drug

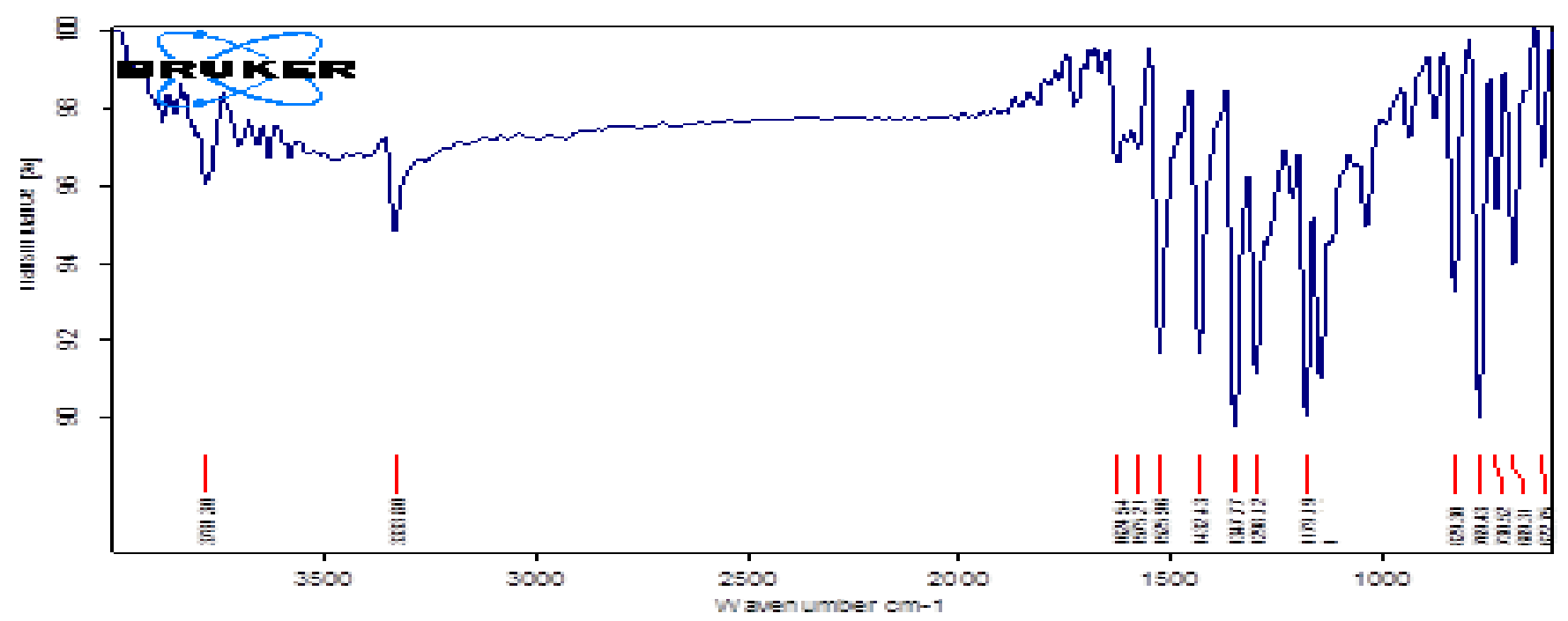

Figure 2: FTIR spectrum of drug and all the excipients used. 
Citation: Madhavi K, Rani SS, Khatoon S, Vijender C (2016) Preparation, Optimization and Characterization of Eudragit Coated Chitosan Piroxicam Microspheres Intended for the Treatment of Rheumatoid Arthritis. Pharm Anal Acta 7: 485. doi:10.4172/2153-2435.1000485

Page 4 of 4

Stability studies were conducted at $40^{\circ} \mathrm{C} / 75 \% \mathrm{RH}$ for 3 months in stability chamber. Samples for 1 month, 2 months, and 3 months were collected and assayed to determine drug degradation during this three month period of stability testing (Table 6).

\section{Conclusion}

An attempt was made to prepare and encapsulate cross-linked chitosan microspheres using emulsion method.

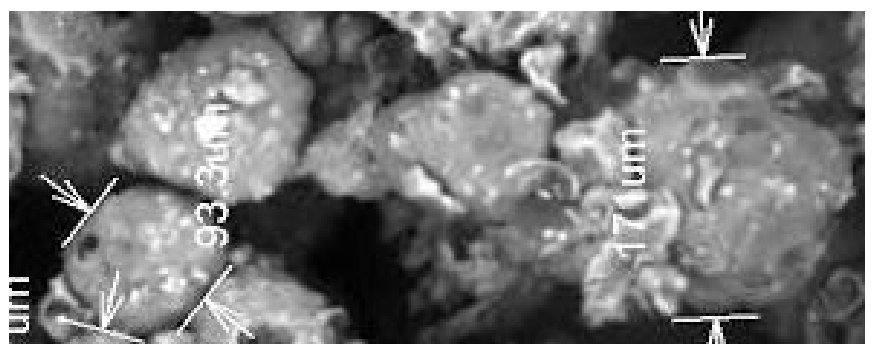

Figure 3: SEM image of optimized formulation

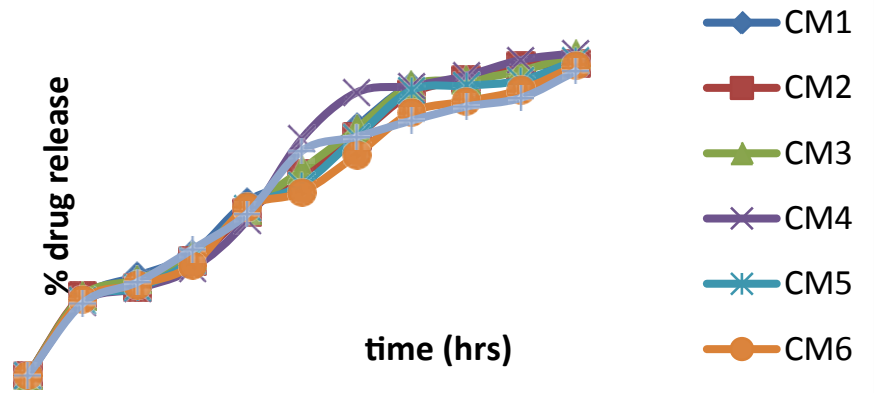

Where CM1-Chitosan microspheres (1: 1), etc.

Figure 4: In vitro drug release pattern of uncoated formulations.

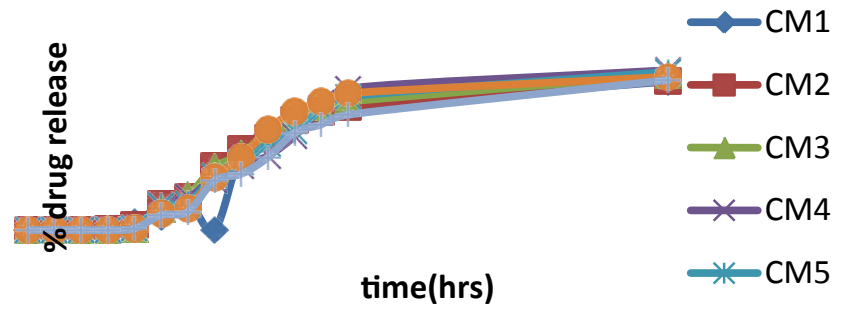

Where CCMI-Coated chitosan microspheres (1:1), etc.

Figure 5: In vitro release pattern of coated formulations.

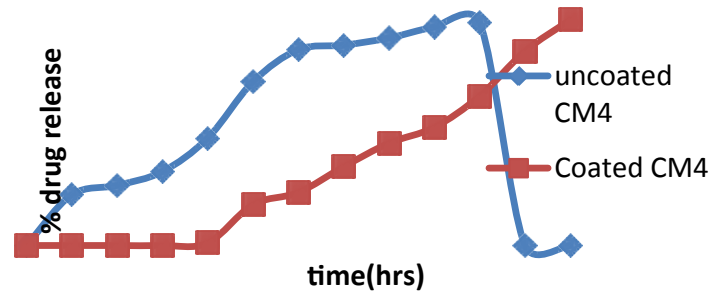

Figure 6: In vitro comparative release profile of uncoated and coated formulation of CM4.

\begin{tabular}{|c|c|c|}
\hline Drug:Polymer Ratio & $\begin{array}{c}\text { Glutaraldehyde volume } \\
(\mathbf{2 5 \%} \mathbf{~ v / v )} \text { in } \mathbf{~ m l}\end{array}$ & $\begin{array}{c}\text { Mean Particle size } \\
\mathbf{( \mu \mathbf { m } )}\end{array}$ \\
\hline $1: 5$ & 2.5 & 86 \\
\hline $1: 5$ & 5 & 84 \\
\hline $1: 5$ & 10 & 82.3 \\
\hline
\end{tabular}

Table 4: Effect of crosslinking agent on particle size.

\begin{tabular}{|c|c|c|c|}
\hline \multicolumn{2}{|c|}{ IR absorption bands of Piroxicam } & \multicolumn{2}{|c|}{$\begin{array}{c}\text { IR absorption bands of prepared } \\
\text { chitosan formulation (1:5) }\end{array}$} \\
\hline -NH & 3333.8 & $-\mathrm{NH}$ & 3357.3 \\
\hline Sec Amine & 1572.3 & Sec Amine & 1587.5 \\
\hline$-\mathrm{OH}$ & 3326.8 & $-\mathrm{OH}$ & 3269 \\
\hline$-\mathrm{C}=\mathrm{C}$ & 1625.7 & $-\mathrm{C}=\mathrm{C}$ & 1631.5 \\
\hline
\end{tabular}

Table 5: IR absorption bands of piroxicam and that of prepared chitosan microspheres $(1: 5)$.

\begin{tabular}{|c|c|}
\hline Time & Assay Value (\%) \\
\hline 1 Month & 99.31 \\
\hline 2 Month & 99.14 \\
\hline 3 Month & 98.92 \\
\hline
\end{tabular}

Table 6: Assay values of the optimized formulation during stability studies.

The prepared microspheres showed good retardation and sustained release for $24 \mathrm{~h}$

Increase in polymer concentration, increased drug entrapment efficiency up to a point then decreased. The other variables like emulsifier concentration, stirring speed and cross-linking concentration also affected entrapment efficiency and drug release.

Formulation 1:5 where polymer is about $400 \mathrm{mg}$ was selected as optimized formulation, it showed $98 \%$ drug release in $24 \mathrm{~h}$ following korsemeyer peppas model with non fickian diffusion mechanism.

Based on the observations it can be concluded that the prepared piroxicam microspheres can show chronopharmacotherapy and with minimal side effects.

\section{Acknowledgement}

The author thanks the director of Care College of pharmacy, Warangal, for providing necessary facilities to carry out this work.

\section{References}

1. Alagusundarum M, Madhusudan M, Umashankar K, Badarinath AV, Lavanya C, et al. (2009) Microspheres as a novel drug delivery system. Internationa Journal of Chemtech Research 1: 526-534.

2. Amandeep K, Hari Kumar SL (2012) Controlled drug delivery approaches for rheumatoid arthritis. Journal of Applied Pharmaceutical Science 5: 21-32.

3. Bhushan Prabhakar K, Kalyani V, Mundhe SV, Lahoti SS (2012) Colon targeted drug delivery system- A novel perspective. Asian journal of biomedical and Pharmaceutical Sciences 2: 21-28.

4. Sangeetha M, Kaur PA (2014) Preparation of 5-flourouracil microspheres for colonic drug delivery. International Journal of Pharmacy 4: 283-296.

5. Roy S, Panpalia SG, Nandy BC, Ravi VK, Tyagi LK, et al (2009) Effect of method of preparation on chitosan microspheres of mefenamic acid. International Journal of Pharmaceutical Sciences and Drug Research 1: 36-42.

6. Srikanth B, Mithu B, Girijesh P, Ameit J, Balakrishna D (2013) Design and development of eudragit coated chitosan microspheres for colon targeted delivery. Journal of Biomedical and Pharmaceutical Research 3: 51-58.

7. Mothilal M, Nagalaxmi M, Swathi PS, Damodharan N, Manimaran V et al (2012) Optimization and characterization of chitosan microspheres of aceclofenac. International Journal of Pharma Sciences and Research 3: 305-315.

8. Pavani S, Deepak K, Sujitha H (2013) Preparation and in vitro evaluation of chitosan microspheres of eplerenone. International Journal of Pharmaceutical Sciences 3: 1-5. 